\title{
НАЦИОНАЛЬНО-КУЛЬТУРНАЯ СПЕЦИФИКА ФУНКЦИОНИРОВАНИЯ КОНЦЕПТА «ЛЮБОВЬ» ВО ФРАЗЕОЛОГИЧЕСКОЙ КАРТИНЕ МИРА
}

Данная статья посвящена рассмотрению особенностей функционирования национально-культурного концепта ЛЮБОВЬ в паремиологических конструкциях и устойчивых выражениях. Акцентуация и актуализация ядерных социально-культурных пространств в ключевых концептуализируемых понятиях каждой из лингвокультур представляет собой одну из наиболее важных проблем современной лингвокультурологии и когнитивной лингвистики. Актуальным является произведенный в рамках исследования контрастивный и компаративный анализ экспликации компонентов семного состава рассматриваемого концепта в картинах мира различных лингвокультурных сообществ. Принципиально новым в работе представляется выявление автором основных векторов накопления изменений информационно-знаниевого континуума в концептуализируемом понятии в процессе взаимодействия языкового знака как его употребления с ментальными образованиями, содержащими социально-культурные элементы. Разработка проблемы осуществляется в рамках лингвокультурного и герменевтического подходов к анализу процессов формирования и динамики пексической экспликации отдельных компонентов когитологических сфер, что доказывает возможность объединения когитологических методов изучения речемыслительных процессов экстериоризации социально-культурной информации и герменевтическо-ноэматических приемов имплементации отдельных обертонов смысловой иерархии при концептуализации понятия.

Ключевые слова: концепт, паремия, фразеологизм, этно-национальная специфика, концептуализация, вербализация.

\section{NATIONAL AND CULTURAL PECULIARITIES OF THE LOVE CONCEPT IN THE PHRASEOLOGICAL PICTURE OF THE WORLD}

The article studies national and cultural features of the LOVE concept as represented in paremiological constructions and set expressions. Actualization and special emphasis on nucleus socio-cultural spaces in the key conceptualized notions in any linguoculture appear to be a topical issue in modern linguoculture studies and cognitive linguistics. The study offers relevant contrastive and comparative analyses of seme component expression as regards the concept under consideration in the pictures of the world within different linguocultural communities. The author provides a completely new specification of basic vectors to accumulate changes in information-knowledge continuum correlating with the conceptualized notion as

В настоящее время не подлежит сомнению постулат о непосредственной и глубокой взаимозависимости формирования и развития некоей этно-национальной общности и динамики развития языковой системы, являющейся примарным кодом аккумулирования и трансляции различных видов информации. Ментальность каждого народа, его этнонациональное сознание, его культурная самоидентификация в качестве общей, разделенной всеми членами сообщества «концептуально-валерной системы» [1] (термин C. Н. Бредихина) образует рефлексивную реальность языка. Так, например, каждая этни- the language sign reveals the interaction between its use and mental constructs containing socio-cultural elements. The analysis rests on linguo-cultural and hermeneutic approaches to studying the processes of formation and dynamics of lexical expression of certain components representing the cogitological spheres. It allows the possibility of combining cogitological methods in studying speech and mental processes of socio-cultural information exteriorization and hermeneutic-noematic techniques of implementing particular overtones of sense hierarchy in the course of notion conceptualization.

Key words: concept, paroemia, phraseological unit, ethnic-national peculiarities, conceptualization, verbalization.

чески- или культурно-единая группа обладает некоторым рядом ассоциатов-экспликаторов образности, основой которого являются единые, стереотипные метафорические модели и специфическое компонентное наполнение лингвем как органичного сочетания языковых значений с объективируемыми мыслительными понятиями [17]. Данные ассоциаты могут, проходя весь процесс концептуализации, закрепляться в системе языка, формируя специфическое этно-национальное ядро концептосферы, дающее возможность каждому из представителей лингвокультуры осознавать и производить коммуникативные действия 
В соответствии с единой ценностно-ориентационной парадигмой.

В настоящей работе мы используем контаминированный когитологическо-герменевтический подход, главной целью которого является определение точек пересечения, синтеза компонентов репрезентации индивидуально-личностного и обще-лингвокультурного в языковых единицах, т.е. совмещение концептосознания и языкосознания в их экспликации в сфере речемысли. Данный вопрос на настоящий момент является приоритетным в лингвокогнитивных исследованиях. Мы же имеем целью рассмотрение вышеозначенных процессов на материале фразеологического состава немецкой, английской и русской систем языка как результата объединения двух коллективных и анонимных феноменов - фольклора и языка. Это универсальное миропонимание, которое сформировалось на основе рефлексии второго уровня ещё на ранней стадии развития национального самосознания, можно отнести к той сорере рефлексивной реальности, которая осознается, как утверждает С. Н. Бредихин, интуитивно как «наиболее общий метасмысл» в каждой конкретной культуре [4, с. 639], что исключает использование более традиционного термина «народное искусство». Подобная картина мира эксплицирует прежде всего компоненты лингвокультурного «коллективного бессознательного». Так, один из ведущих советских исследователей фольклора А. П. Скафтымов дефинирует фольклорную мысль как некое «творческое искажение жизни» $[14$, с. 56], дающее реципиенту идеализированное, свободное от наслоений объективной реальности, случайных наслоений, представление конкретного этно-культурного сообщества о мире - некую идеальную стереотипную модель недостижимую, но определяющую все действия человека "концептуально-валерную систему" [1] норм и правил. Это своего рода этнический эталон культуры-носителя, создающийся на основе всех возможных употреблений ментального стереотипа в процессе речевых экспликаций. Этот процесс имеет чрезвычайно сложную структуру, по С. Н. Бредихину, формирующееся в первую очередь при контакте реципиента с действительностью, «внутреннее понятие» [1, с. 123] входит в рефлексивную реальность индивидуума, затем реализуется в различных ментальных конструкциях и порождает «невербализованное понятие» [1, с. 123], которое ищет пути собственной репрезентации в структурах языка и формирует реслексивную базу "вербализованного понятия", которое в свою очередь переосмысливается в процессе многочисленных речеупотреблений, обретает дополнительные обертоны смысла, кристаллизуемые в ядре «концептуализированного понятия» $[1$, с. 123] приобретающего статусные характеристики в концептуально-валерной системе. Разработка вопроса предельной концептуализации в паремиологии и фрразеологии открывает перед нами широкие перспективы анализа этно-культурных компонентов базовых ценностных категорий определенного языкового сообщества.
В рамках данной концепции можно установить и связь предпринятого анализа с исследованиями в области лингвокультурологии, Так, С. Г. Тер-Минасова подчеркивает возможность языка функццинировать в качестве «зеркала культуры ) [15, с.48] способного отражать не только действительность (воспринимаемую и трансформируемую человеком в процессе предметной деятельности), но и рефлексивную реальность (сировоззрение, ценностно-ориентационную сферу, менталитет, социо-культурные традиции в рамках коммуникативного поведения).

Из постулата о диалектическом взаимодействии мышления и языка, мы заключаем, что язык отражает языковую картину мира как народа в целом, так и особенности познавательной деятельности человека и его мышления. Трудно не согласиться О. Д. Ивицкой, утверждающей интерпретативный и знаково-символьный характер языковой картинь мира по отношению к объективной реальности. И в то же время необходимо подчеркнуть примат концептуальной картины мира в языковой системе, отражающей весь сонм характеристик человеческой экзистенции, взаимосвязь и взаимопроникновение данной системы и реального мира в терминах условий человеческого и языкового бытования в этом мире [8, с. 122].

Понятие «языковая картина мира» мы тесно связываем с понятием ментальности, которую можно понимать, как мировидение, репрезентированное в категориальных понятиях и формах языковой системы, которые являются ключевыми точками бифуркации духовных, волевых и интеллектуальных качеств этно-национального характера, при этом культурный концепт будет служить основным элементом ментальности [11, с. 127].

Вслед за Д. С. Лихачевым можно определить концепт как некий продукт тесного взаимодействия значения лексемы и его контекстуального употребления в лингвокультурном сообществе, т.е. потенциальный объем концепта находится в прямой зависимости от индивидуально-личностного и этно-национального культурного опыта [10, с. 189].

Необходимо отметить, что фразеологический уровень, являясь этноспецифическим сводом законов данного народа - этническим эталоном, который отражает не только сами процессы построения лингвокультурного семантического пространства, но и является собственно их результатом, а также репрезентирует в своей иерархической структуре ценностно-этические и социально-нравственные составляющие. Морально-нравственные принципы идейно фрормализуются на основе идеалов добра и зла, справедливости, долга, и соотносятся с конкретным периодом и формой общественного строя и развития, т.е. представляют ядро эпистемы. Нравственные нормы формируются в течение продолжительного периода времени на основе традиций, обнаруживающихся у каждого конкретного этноса или народа. При этом обычаи и традиции различных этнических общностей не существуют изолировано в когнитивно-валерном пространстве одной лингвокультуры - они вза- 
имодействуют, взаимообогащаются, воспринимают элементы других, не теряя при этом свойственных принимающей лингвокультуре базовых (ядерных) характеристик [3, с. 32-33].

В рамках анализа репрезентационных потенций концептуализированного понятия ЛЮБОВЬ (одного из ядерных в рассматриваемых лингвокультурах - немецкой, русской и английской) следует, прежде всего, остановится на универсальных моделях деривации этно-культурных обертонов смысла во фразеологическом аппарате данных языковых систем. В действительности, на достаточно обширном эмпирическом материале паремических систем разных лингвокультур можно обнаружить единые тенденции в производстве как деятельностных, так и коммуникативных актов, т.е. сходство большинства «сюжетов» представления этнических стереотипов. Однако необходимо подчеркнуть не только различную степень их актуализации, но и собственные, культурно-специфические основы перехода стереотипного образа (когитемы) в речевую представленность (овеществление его с помощью локутемы и коммуникемы) и последующего формирования «концептуализированного понятия» [1, c. 123] - лингвемы. Данная разница в, казалось бы, универсальных моделях представления корениться в имманентной связи средств вербализации не только с языковыми возможностями, но и с достаточно тесной переплетенностью их с деятельностной активностью в объективной реальности: образом жизни этноса, природой и климатом конкретного ареала. Взаимообусловленность объективных экстралингвистических факторов и конкретных особенностей лингвокогнитивного конструирования высказывания, социо-культурных и концептуально-валерных аспектов коммуникативного действия всех членов лингвокультурного сообщества закономерно эксплицируется в паремиологической системе языка. Благодаря своей специфике в аспекте стереотипной структурной организации и семантической оформленности в элементах, понятных каждому представителю лингвокультуры, рассматриваемые языковые знаки отличаются тем, что представляют не только референциальную вербализацию некой стереотипной ситуации, но, кроме того, одновременно эксплицируют аксиологические обертоны и «прогностические стратегии» $[1$, с. 122] рецепции и интерпретации данных единиц.

В процессе анализа этно-культурной специфики концептуализированного понятия доминантной представляется рассмотрение его места и валерности (значимости) в концептосфере конкретной лингвокультуры. Устойчивые выражения нередко представляют собой специфические комплексные знаки, эксплицирующие одновременно модели стандартных предметно-деятельностных и коммуникативных ситуаций, а также ассоциативных корреляций дискретных феноменов реальной и рефлексивной действительности. Символический характер, предельная стандартизованность вкупе с возможностью алгоритмизирования процессов рецепции и интерпретации обеспечивают тесную взаимосвязь паремических единиц с общими для всех представителей лингвокультуры когнитивными основаниями мировосприятия. Следует, однако, подчеркнуть разность базовых категорий для формирования внутренней структуры пословичных единиц, т.е. специфику метафорических порождающих моделей - паремии как языковые знаки входят в систему языка, но в качестве прототипических моделей оценки они являются прерогативой фольклорного фонда. Для глубокого понимания рассматриваемого фонда как отдельного пласта языка необходимо делимитировать их место в системе. Паремии, представляя некий целостный фольклорный текст, гораздо сложнее других фразеологических единиц, это, по сути, самостоятельные языковые единицы, выделяемые в отдельный класс. Г. Л. Пермяков постулирует наличие отдельного «паремиологического уровеня языка» $[13$, с. 137] В системе лексических субуровней языка он занимает самый верхний ярус, базирующийся на «нижнем» - лексическом, способным выразить любые отношения и понятия, включая те, которые находят экспликацию во фразеологизмах, «среднем» - фрразеологическом, который является существенным дополнением тезауруса и обеспечивает лексико-фразеологический состав языка комплексными знаками-вербализаторами специфических или же прототипических концептуально-нагруженных ситуаций-понятий. Рассматриваемый нами «верхний» паремиологический уровень, который включает в себя поверья, велеризмы, присловья, приметы, пословицы и поговороки и т.п. является арсеналом языковых и речевых (в их транссормированном переосмысленном виде) единиц, призванных вербально эксплицировать типовые ситуации бытования человека, в аспекте формирования и наиболее простого (на уровне ноэматической рефлексии) усвоения множества логических норм наивной картины мира.

В целом сонме разноструктурных и обладающих различной степенью стереотипности произведений народного творчества особое место отводится именно пословицам и поговоркам как наиболее общим, несмотря на их ограниченное функционирование в речи, разделенным всеми членами лингвокультурного сообщества экспликаторам «житейского» знания. Данный фракт объясняется предельной концентрацией в вербализуемом понятии генерализованного концептуально-художественного образа, который призван отражать различные феномены быта в их наивном миропонимании, на основе общекультурной интуитивной рефлексии. Весь пословичный фонд представляет собой некий глубинный аксиологический код, воспринимаемый отдельным языковым сообществом как “свод суждений о жизни народа, свод точных и острых характеристик, наблюдений и обобщений, сделанных трудящимися массами; в пословицах отражены и ошибочные, ложные толкования окружающего мира, и ложные знания, которые постепенно накапливались и получили образное выражение» [2, с. 8]. Паре- 
миологический состав языка раскрывает сложное и часто противоречивое в диахроническом срезе мировоззрение этноса.

В процессе анализа эмпирического материала выявляется несколько положений. Во-первых, концепт ЛЮБОВЬ эксплицируется во фразеологическом составе языка на основании целого ряда ассоциативных лексем, имеющих общее ядро, представленное ноэмами «привязанность», «ценность». Следует отметить имманентную оппозицию, неизменно содержащуюся в данном концептуализируемом понятии - это абстрактность/конкретность сенсуально-аксиологических характеристик. Так, в западноевропейских лингвокультурах предпочтение отдается прямой номинации абстрактного действенного компонента, например, англ. love, или нем. die Liebe; в русском языке ядерная номинация осуществляется в глагольной форме - любить. Во-вторых, степень абстрактности варьируется в различных лингвокультурах: наибольшей степени экспликации обобщенность концептуализации достигает в немецком языке, в то время как в русском языковом пространстве конкретно-деятельностный элемент является доминирующим. В-третьих, некоторые из актуализируемых обертонов в периферийных лексемах лексико-семантической группы «любовь) в русской системе пословиц и поговорок, получают больший приоритет в сравнении с ядерными компонентами реализации концепта ЛЮБОВЬ (любимый, милый сердцу и т.п.). Например, акцентуация ноэм «духовная близость», «единение» в лексеме дружок, указывает на примарность данных элементов смысла в архетипическом понятии любовь. Сама номинация «любовь» в глагольной вербализации является знаком двунаправленного взаимного действия, т.е. эксплицирует и субъект и объект. При этом следует особо подчеркнуть этно-культурные различия в частотности субъектной вербализации в английской и немецкой языковой общности и объектные характеристики, присущие русской лингвокультуре. Результаты функционального ноэматического анализа позволяют утверждать, что концепт ЛЮБОВЬ в ментальном лексиконе германских народов является особой деятельной сущностью, а у русских это имманентная характеристика конкретной личности.

Интересны и концептуальные метафоры, на основе которых каждый народ создавал данные паремии. Они вербализуют похожие ситуации во всех сравниваемых языках, однако, метафоризация осуществляется на базе разных образов, что происходит по причине расхождения в образных ассоциациях в конкретных языковых сообществах, базирующихся на объективных условиях жизни. Так, например, невозможность и противоестественность возникновения чувства любви по принуждению или вынужденности проявления отдельных её характеристик внешними обстоятельствами зачастую вербализуется в русскоязычной лингвокультуре метафорой милостыни или снисхождения: Любовь не милостыня: её каждому не подашь [6, с. 134]. Проявление данных архетипических признаков в немецкой лингвокультуре строится уже на других когнитивных основаниях сравнение с песней: Lieben und Singen lasst sich nicht zwingen [2, с. 76], отмечается и недолговечность любви насильственной: Gezwungene Liebe und gemalte Wange dauern nicht lange [18, с. 230]. Модели метафоризации немецких и английских фразеологизмов, строящиеся на базе герменевтического круга и повтора, эксплицируют взаимность в любовных отношениях: Love is the mother of love [19, c. 184]; Die Liebe ist der Liebe Lohn [2, c. 78].

При всей очевидной универсальности ситуаций каждая лингвокультура обладает и специфическими образными ассоциатами, участвующими в репрезентации концепта ЛЮБОВЬ, отражающими этно-национальные аспекты любовных отношений. Так, например, в немецкой культуре сравнение любви с дымом вербализует невозможность сокрытия глубокого чувства: Liebe und Rauch schauen zum Fenster hinaus [18, c. 232]. Для англичан те же смыслы несет сравнение с бедностью: Love and poverty are hard to hide [19, с. 189]. В немецкой лингвокультуре неотъемлемой спутницей любви (в её архетипическом восприятии) является верность: Treve ist eine Schwester der Liebe [2, с. 79], равно как и «потеря рассудка» в ситуации влюбленности: Liebe und Verstand gehen selten Hand in Hand [18, с. 234]. В русскоязычном лингвокультурном пространстве с учетом ассоциативного ряда традиционных патриархальных ассоциатов и в контексте произведений классической художественной литературы, феномен любовь имеет специфические, часто негативные ноэмы в структуре глубинного содержания, что вербализовано в пословицах и поговорках, например, Любовь - крапива стрекучая (актуализация ноэмы «страдание»); или же Любовь не пожар, а загорится - не потуиишь (актуализация ноэмы «стихия», «буйство», «всепоглощение») [6, с. 134]. В рамках исследования характера экспликации концепта ЛЮБОВЬ в паремиях сравниваемых лингвокультур нами применялся и сравнительный анализ, что в свою очередь повысило эффективность концептуального анализа

Вслед за С.Н. Бредихиным, под концептуально-валерной системой мы будем понимать «целеустановки, идейно-эстетические представления и их резонанс, или же отсутствие такового с идейно-эстетической направленностью» [5, с. 210], а также специфическую правилосообразную нравственную деятельность, выраженную в форме успешного или неуспешного коммуникативного акта в рамках конкретной лингвокультуры.

Также следует подчеркнуть, присутствие в общей структуре смысла множества кластеров объективизации и актуализации в первичном понятии, а затем в фразеоме или лексеме одного и того же фрагмента картины мира. При этом потенции в членении общего когнитивно-коммуникативного пространства на паремиологический и фразеологический уровень зависят от используемого в конкретном типе дискурса вида кластера. 
В рамках адекватной интерпретации глубинного смысла паремического выражения (вне зависимости от традиционности или трансформированности формы) доминантами будут служить внешние контекстуальные факторы этно-культурной реализации, такие как: условия общественной жизни, этнопсихотипы каждого конкретного этноса, степень индивидуализации и традиционности. В процессе производства многомерного, иносказательного, трансформированного, а значит продуктивного традиционно-неопределенного смысла, что часто происходит при использовании паремий вне стереотипного контекста, в качестве доминантных следует рассматривать именно концептуальные компоненты, обеспечивающие возможность понимания генерализованного смысла всеми членами языкового сообщества и способствующие формированию над-линейных «иерархических ноэматических суперструктур на уровне целостного и непротиворечивого восприятия текстовой реальности, и которые играют первостепенную роль в смысловой наполненности» [4, с. 642]. Ведь базой паремий и фразеологизмов служат именно культурные этноконцепты. По справедливому утверждению Е. А. Мокрушиной, "лежащие в их основе нравственные категории будучи универсальными по своей природе, детерминируются культурно-исторически в рамках определенной языковой культуры, накладывающей также отпечаток на способы осрормления концептов в языке» $[12$, с. 74$]$.

Таким образом, мы пришли к следующим выводам: концепт ЛЮБОВЬ может быть отнесен к базовым в концептуально-валерной системе каждой из изученных лингвокультур как высшая моральная ценность, обладающая максимальной валерностью в системе приоритетов лингвокультурной общности. Необходимо учитывать тот факт, что на этноспецифичность фразеологического кода влияют не только процессы и результаты построения семантического пространства, но и социальные и этические факторы [16, с. 114]

Можно констатировать, что фразеологический состав любой языковой системы вообще, и паремиологический его пласт в частности, образуют базу концептуально-валерной системы на основе эмотивно-психологического аксиологического кода. Данное ядро мирооценки функционирует в его вербальном представлении на лексическом уровне языковой системы, давая конкретному этносу, объединенному общим лингвокультурным пространством, единые верования, мировидение, традиции, обычаи, мифы и фантазии.

Классификацию концептуально-валерных формантов можно представить в виде иерархии личностных, социальных и высших морально-нравственных ценностей. В сферу личностных ценностей входят наилучшие индивидуальные качества личности (мужество, доброта, интеллект, твердость духа и т.п.). Социальные ценности определяются такими характеристиками, как отношение к отечеству, работе, семье и другим социальным институтам. К высшим моральным ценностям можно отнести нравственные свойства, обладающие максимальной аксиологической нагрузкой в системе моральных приоритетов лингвокультурного сообщества: честь, долг, свобода и любовь [9, с. 117]. Однако следует сказать, что в отличие от индивидуально-авторского порождения экспликатора «не житейской», традиционно не укорененной ситуации, процесс рождения глубинного смысла устойчивого выражения в рамках имманентно присущей полилогичности является актом совместного производства и осмысления как объективной, так и рефлексивной реальности - это процесс поиска совместного ответа лингвокультурного сообщества на единый онтологический вопрос. Именно как результат данного поиска и возникает материализованное в вербалике стереотипное коммуникативное действие преображенное и упорядоченное средствами языка «индивидуально-субъективный и в то же время общий для автора и читателя мир» [4, с. 641].

Таким образом, можно констатировать, что этно-культурные аспекты функционирования концептуализированного понятия ЛЮБОВЬ вносят значительный вклад в формирование прогностических стратегий рецепции и интерпретации осложненных коммуникативных действий в рамках стереотипного поведения и использования паремических единиц для вербализации традиционно-значимых, ситуативно-прагматических ценностных аспектов эмоционально-психологической сферы. Следует отметить примат пословичного состава над другими как устойчивыми, так и свободными сочетаниями в вербально-коммуникативном представлении «житейской мудрости» определенного этноса

\section{Литература}

1. Аликаев Р. С., Бредихин С. Н. «Схемы действования» как маркер дискурсивности научного текста: формальная логика vs. герменевтика // Вестник Волгоградского государственного университета. Серия 2: Языкознание. 2015. №2 (26). C.121-127.

2. Бинович Л. Э., Гришин Н. Н. Немецко-русский фразеологический словарь. М.: Русский язык. 1975. 656 с.

3. Бобрышева Л. К. Фразеологизмы как национально-культурная экзистенциональная картина мира (на материале русского и адыгейского языков): дис. ... канд. филол. наук. Майкоп, 2009. 168 с.

4. Бредихин С. Н., Вартанова Л. Р. Текстологические функции иносказательных переосмысленных конструкций в смыслообразовательном аспекте // Фундаментальные исследования. 2015. № 2-3. С.639-643.

5. Бредихин С. Н., Давыдова Л. П. Поэтический текст как коммуникативно-эстетическая категория // Гуманитарные и юридические исследования. 2016. №2. С.210-216.

6. Даль В. И. Пословицы русского народа. М.: Русский язык, 1986.670 с

7. Даль В. И. Толковый словарь живого великорусского языка. М.: Русский язык, 1981.699 с. 
8. Ивицкая О. Д. К вопросу о национальной языковой личности и различиях в номинативных картинах мира (на примере Великобритании) // Юбилейный сборник статей. М.: Школа Китайгородской, 2000. С.122-130.

9. Кунин А. В. Курс фразеологии современного английского языка: учебник для студентов институтов и фак-в иностранных языков. М.: Высш. школа, 1996. 380 с.

10. Лихачев Д. С. Концептосфера русского языка // Русская словесность: От теории словесности к структуре текста: антология. М.; Наука, 1997. С.280-287.

11. Маслова В.А. Лингвокультурология. М.: Академия, 2001. 208 с.

12. Мокрушина Е. Ю. Концепт «добрый» как этический феномен лингвокультуры: на материале английского языка. дис. ... канд. филол. наук. Кемерово, 2008. 196 с.

13. Пермяков Г. Л. Основы структурной паремиологии. М.: Наука, 1988. 236 с.

14. Скафтымов А. П. Поэтика и генезис былин. Саратов: В. З. Яксанов, 1924. 228 С.

15. Тер-Минасова С. Г. Язык и межкультурная коммуникация. М.: Слово, 2000. 262 с.

16. Трахова А. Ш. Фразеологическая концептуализация морально-нравственной сферы личности и народа: мифолого-религиозные и этнокультурные основания (на материале русского и адыгейского языков). Краснодар: Кубанский roc. УH-T, 2006. $251 \mathrm{C}$

17. Фефилов А. И. Введение в когитологию. М.: Флинта: Наука, 2010. 240 с.

18. Duden C. Deutsches Universalwörterbuch. Mannheim-Leipzig-Wien-Zürich: Dudenverlag von Drosdowski, 2005. $630 \mathrm{~S}$.

19. Margulis A., Kholodnaya A. Russian-English Dictionary of Proverbs and Sayings. London McFarland \& Company, Inc., Publishers Jefferson, 2000. 487 c.

\section{References}

1. Alikaev R. S., Bredikhin S. N. «Skhemy dejstvovaniya» kak marker diskursivnosti nauchnogo teksta: formal'naya logika vs. germenevtika ("Schemes of acting" as a discourse marker of a scientific text: formal logics vs. hermeneutics) // Vestnik Volgogradskogo gosudarstvennogo universiteta. Seriya 2: Yazykoznanie. 2015. No.2 (26). S.121-127. (In Russian).

2. Binovich L. E., Grishin N. N. Nemetsko-russkij frazeologicheskij slovar' (German-Russian phraseology dictionary). Moscow: Russkij yazyk, 1975. 656 p. (In Russian).

3. Bobrysheva L. K. Frazeologizmy kak natsional'no-kul'turnaya ehkzistentsional'naya kartina mira (na materiale russkogo i adygejskogo yazykov) (Phraseology as national and cultural existential worldview (as exemplified in Russian and Adyghe) thesis. Majkop, 2009. 168 p. (In Russian).

4. Bredikhin S. N., Vartanova L. R. Tekstologicheskie funktsii inoskazatel'nykh pereosmyslennykh konstruktsij $v$ smysloobrazovatel'nom aspekte (Textual functions of allusive contemplative phrases in sense-making) // Fundamental'nye issledovaniya (Fundamental research). 2015. No.2-3. P.639-643. (In Russian).

5. Bredikhin S. N., Davydova L. P. Poehticheskij tekst kak kommunikativno-ehsteticheskaya kategoriya (Poetic text as communicative-aesthetic category) // Gumanitarnye i yuridicheskie issledovaniya. 2016. No.2. P.210-216. (In Russian).

6. Dal' V. I. Poslovitsy russkogo naroda (Proverbs of Russian nation). Moscow: Russkij yazyk, 1986. 670 p. (In Russian).

7. Dal' V. I. Tolkovyj slovar' zhivogo velikorusskogo yazyka (Explanatory Dictionary of the Live Great Russian Language). Moscow: Russkij yazyk, 1981. 699 p. (In Russian).

8. Ivitskaya O. D. K voprosu o natsional'noj yazykovoj lichnosti i razlichiyakh v nominativnykh kartinakh mira (na primere Velikobritanii) (Revised national linguistic persona and differences in nominative world views (as exemplified in Great Britain)) // Yubilejnyj sbornik statej (Jubilee volume of articles). Moscow: Shkola Kitaigorodskoj, 2000. P.122 - 130. (In Russian).

9. Kunin A. V. Kurs frazeologii sovremennogo anglijskogo yazyka (Course of modern English phraseology). Moscow: Vyssh. shkola, 1996. 380 p. (In Russian).

10. Likhachev D. S. Kontseptosfera russkogo yazyka (Concept sphere of Russian language) // Russkaya slovesnost': Ot teorii slovesnosti k strukture teksta: antologiya. Moscow: Nauka,1997. P.280-287. (In Russian).

11. Maslova V. A. Lingvokul'turologiya (Linguoculturology). Moscow: Akademiya, 2001. 208 p. (In Russian).

12. Mokrushina E. Yu. Kontsept «dobryj» kak ehticheskij fenomen lingvokul'tury: na materiale anglijskogo yazyka. (Concept "Kind" as ethic phenomenon of linguoculture: as exemplified in Russian): thesis. Kemerovo, 2008. 196 p. (In Russian).

13. Permyakov G. L. Osnovy strukturnoj paremiologii (Fundamentals of structural paramiology). Moscow: Nauka, 1988. 236 p. (In Russian).

14. Skaftymov A. P. Poehtika i genezis bylin (Poetics and heroic epic ballade genesis). Saratov: V.Z. Yaksanov, 1924. 228 p. (In Russian).

15. Ter-Minasova S. G. Yazyk i mezhkul'turnaya kommunikatsiya (Language and cross cultural communication). Moscow: Slovo, 2000. 262 p. (In Russian).

16. Trakhova A. Sh. Frazeologicheskaya kontseptualizatsiya moral'no-nravstvennoj sfery lichnosti i naroda: mifologoreligioznye i ehtnokul'turnye osnovaniya (na materiale russkogo i adygejskogo yazykov) (Phraseological conceptualization of moral ethical sphere of person and nation: mythological religious ethnic cultural basis (as exemplified in Russian and Adyghe)). Krasnodar: Kubanskij gos. un-t, 2006. 251 p. (In Russian).

17. Fefilov A. I. Vvedenie v kogitologiyu (Introduction to cogitology). Moscow: Flinta: Nauka, 2010. 240 p. (In Russian)

18. Duden S. Deutsches Universalwörterbuch. Mannheim-Leipzig-Wien-Zürich: Dudenverlag von Drosdowski, 2005. $630 \mathrm{~s}$

19. Margulis A., Kholodnaya A. Russian-English Dictionary of Proverbs and Sayings. London McFarland \& Company, Inc. Publishers Jefferson, 2000. 487 p.

\section{Информация об авторах}

Маринина Галина Ивановна - кандидат филологических наук, доцент кафедра теории и практики перевода гуманитарного института Северо-Кавказского федерального университета (Ставрополь) / gala81 @list.ru 
Писклова Марина Витальевна - ассистент института лингвистики и межкультурной коммуникации Первого Московского государственного медицинского университета им. И.М. Сеченова (Mockва)/ marinapisklova@mail.ru

\section{Information about the authors}

Marinina Galina - PhD in Philology, Associate Professor, Chair of Translation Studies, Institute of Humanities, NorthCaucasus Federal University (Stavropol) / gala81@list.ru

Pisklova Marina - teaching assistant, Institute for Linguistic and Intercultural Communication, I.M. Sechenov First Moscow State Medical University (Moscow) / marinapisklova@mail.ru 